\title{
La actividad deportiva, sociabilidad e identidades en Cuba en el periódico El Sport (1886-1888)
}

\section{Sporting activity, sociability and identities in Cuba in El Sport newspaper (1886-1888)}

Chester Urbina Gaitán

Universidad Estatal a Distancia curbina@uned.ac.cr

\begin{abstract}
Resumen
La actividad deportiva en Cuba entre 1886 a 1888 se ubicó en el occidente desde Sancti Spiritus hasta Pinar del Río, debido a que en esta parte de la isla se concentraba el capital y la infraestructura necesaria para ejecutar prácticas deportivas. La ejecución del deporte se realizó en el ámbito de lo privado. La vida deportiva cubana de los años de estudio fue muy intensa, debido a la gran influencia cultural y a la cercanía con los Estados Unidos. La práctica de las diferentes disciplinas fue acaparada por la nobleza española y la elite económica cubana junto con algunos grupos miembros de las colonias estadounidenses y europeas. Con respecto al beisbol, su popularidad se debió a que reforzó el sentimiento local entre poblaciones como La Habana, Matanzas, Pinar del Río y Cárdenas. Asimismo su expansión radicó en que permitió, la práctica de personas negras y de la niñez, incluyó a las mujeres como socias honorarias y dedicó partidos a la beneficencia. La actividad deportiva fue controlada principalmente por varones debido a la visión sexista que existía de esta misma.
\end{abstract}

Palabras clave: élite cultural, racismo, masculinidad, concentración geográfica, beisbol. 


\begin{abstract}
The sporting activity in Cuba from 1886 to 1888 was located in the west from Sancti Spiritus to Pinar del Río, because in this part of the island the capital and infrastructure necessary to execute sports practices were concentrated. The execution of the sport was done in the private sphere. The Cuban sports life of the years of study was very intense due to the great cultural influence and the proximity with the United States. The practice of the different disciplines was monopolized by the Spanish nobility and the Cuban economic elite along with some members of the American and European colonies. With respect to baseball, its popularity was due to the fact that it reinforced the local feeling among populations such as La Habana, Matanzas, Pinar del Río and Cárdenas among others. Also its expansion was that it allowed the practice of blacks and children, included women as honorary members and dedicated parties to charity. The sport activity was controlled mainly by men due to the sexist vision that existed of the same one.
\end{abstract}

Keywords: Cultural elite, racism, masculinity, geographical concentration, baseball.

\section{Introducción}

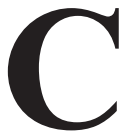
uba, en el siglo XIX, era una de las últimas posesiones del imperio español y se vinculó al sistema capitalista mundial a través del cultivo de la caña de azúcar. Esta unión económica se dio a través de la esclavitud. Empero, fue hasta 1886 cuando en la isla se produjo su abolición. Esto marcó la vida de este país a finales del siglo XIX, en el sentido de que para resolver el problema de la falta de mano de obra y blanquear y españolizar la población, la elite política trató de reducir la influencia del elemento negro y fortalecer el dominio colonial. Para alcanzar este objetivo, la solución escogida fue fomentar y controlar la inmigración (García Alvarez, 1993; García Álvarez y Naranjo, 1998; Guanche, 1997; Gutiérrez y Laviana, 1998; Iglesias, 1997; Losada,
1994; Naranjo y Mallo, 1994; Pujol, 1998; Rodríguez Piña, 1990; Tornero, 1998). Después de la primera guerra de independencia cubana (1868-1878), la sociedad civil comenzó a fortalecerse en respuesta a las condiciones laborales y a la política reformista española, donde jugaron un papel importante las sociedades mutualistas, benéficas y recreativas (Barcia, 1998).

Sobre el inicio de las prácticas deportivas en la ciudad de México, se sabe que entre 1851 a 1910 estas surgieron en el seno de la burguesía capitalina mexicana y de las principales colonias extranjeras radicadas en esa urbe, como la inglesa, la estadounidense, la española, la alemana, la francesa y la japonesa. Dentro de estos años nacieron disciplinas deportivas como las carreras de caballos, esgrima, gimnasia, natación, boliche, regatas, pelota vasca, 
ajedrez, ciclismo, boxeo, lucha grecorromana, atletismo, beisbol, patinaje, fútbol, golf, jiu jitsu, criquet y tenis. En sus orígenes en la capital mexicana, el deporte moderno estuvo dominado por disciplinas individuales, lo cual hizo que los sectores que comenzaron a ejercitarse en ellas, consideraran su práctica como un acto social, por lo que la adecuada preparación $\mathrm{y}$ entrenamiento estuvieron en una gran medida ausentes. Con el surgimiento del beisbol en 1897, los sectores trabajadores urbanos toman parte en la práctica del deporte; ante esto se puede considerar que este deporte contribuyó en la formación de un sentido de clase entre esos grupos sociales. Sin embargo, la mala organización y la pobreza de sus organizaciones, el poco apoyo de líderes comunales, tanto seculares como religiosos, así como la no existencia de campos adecuados para las prácticas, hicieron que sus asociaciones deportivas tuvieran en general una existencia corta (Urbina Gaitán, 2015).

La introducción del deporte en países centroamericanos como Costa Rica, Guatemala y El Salvador indica que esta actividad cultural estuvo relacionada con las prácticas que hacían a finales del siglo XIX las principales colonias extranjeras radicadas en esos países. Debido a sus lazos socioafectivos con las burguesías nacionales y a sus intereses comerciales en torno al café y al banano, se explica el hecho de que los primeros clubes deportivos de estos países reforzaran la identidad de clase de esos sectores. Todo lo antes señalado sirve de sustento para indicar que las primeras asociaciones deportivas centroamericanas se dedicaron a actividades que solo estaban al alcance de sus integrantes, debido a que estos grupos tenían el suficiente tiempo libre, dinero y preocupación por su salud y apariencia física, aspectos que les permitirán sostener sus asociaciones, las cuales mantenían un carácter clasista y exclusivo (Urbina Gaitán, 2001, Urbina Gaitán, 2006 y Urbina Gaitán, 2007).

Con respecto a la llegada del deporte a Cuba, Douglas Crispín Castellanos, en su artículo: "Desarrollo deportivo cubano antes y después de 1959", refiere que en 1839 el Dr. José de Castro fundó en La Habana el gimnasio Normal. En el siglo XIX se opera un cambio educativo fundamental en la isla, donde la clase dominante ya no asiste a las universidades de Europa, sino a las de Estados Unidos. Esto provocó que la juventud que estudiaba en Estados Unidos introdujera en Cuba el beisbol en la década de 1860, lo que culminó en 1879 con el primer campeonato oficial celebrado en el país. Por otra parte, la gimnasia o "gimnástica" y la esgrima, la ejecutaban jóvenes que habían ido a estudiar a Europa. Los gimnasios comienzan a establecerse a partir de 1880 con la ayuda del Dr. Luís de Agüero. Para 1884 se funda el club Náutico de Santiago de Cuba, en 1888 se establece el club de Esgrima de la Habana y el Habana Yacht Club se crea en 1895 (Crispín Castellanos, s. f.).

En esta investigación se precisarán las fechas de fundación de las asociaciones deportivas antes mencionadas. Para el caso del beisbol existen los libros siguientes: el de Roberto González Echevarría del 2004 titulado La gloria de Cuba: Historia del beisbol en la isla; el publicado el 2006 de Peter C. Bjarkman, A History of Cuban Baseball, 1864-2006, y el de Juan 
A. Martínez de Osaba, Félix Julio Alfonso López y Yasel Porto Gómez, Enciclopedia biográfica del béisbol cubano que vio la luz en al año 2015. Estas obras recogen los principales datos históricos de este deporte en Cuba, donde, de una manera anecdótica, se narran los principales hechos deportivos del beisbol cubano junto con las biografías de los mejores peloteros nacionales. Sin embargo, estas obras no explican qué es lo que diferencia al beisbol del resto de disciplinas que se practicaban en Cuba en el siglo XIX (Bjarkman, 2006; González Echevarría, 2004; Martínez de Osaba, Alfonso López y Porto Gómez, 2015). Fundamentado en todo lo anterior, el presente artículo tiene como objetivo responder las siguientes preguntas: ¿Cuál fue el recorrido histórico del deporte cubano entre 1886 y 1888 ? ¿Qué disciplinas se practicaron en estos años? ¿Qué diferencia al beisbol del resto de deportes? ¿Qué papel tuvo la mujer cubana en la práctica del deporte? Para responder estas interrogantes se utilizará el periódico cubano $\mathrm{El}$ Sport durante sus tres primeros años de circulación, entre 1886 y 1888 , el cual constituye una fuente única y detallada para conocer la evolución del deporte en Cuba desde su introducción a principios del siglo XIX hasta 1888. Al ser Cuba principalmente La Habana- la puerta de entrada de productos y artefactos culturales de Europa y Estados Unidos -entre ellos el deporte- hacia México, Centroamérica y el resto de las Antillas, este estudio reviste una importancia fundamental para entender cómo fue apropiada y conceptualizada esta actividad cultural en sus primeros años de ingreso a América Latina, y su papel en la socialización y en la creación de identidades desde la comunal, de clase, de género, de etnia y la nacional.

\section{Deporte, concentración geográfica e identidades en Cuba (1886-1888)}

En 1886 sale a la luz el semanario El Sport -aunque de este año solo se dispone ejemplares a partir del 5 de agosto- que era el órgano oficial de la Liga General de Base Ball, del Club de Ajedrez de La Habana, del Habana Yatch Club, del Club de Esgrima, del Jockey Club de Colón y de la Sociedad de Caza de La Habana. Sus directores eran Aurelio Granados y Ezequiel García, los redactores eran Héctor de Saavedra, Alberto Ponce, Miguel Palmer, Arturo Riquelme y Teodoro Rossignoli. El periódico contaba con los siguientes colaboradores: Armenio N. Litz, el Marqués de Esteban, Juan F. Centelles, Miguel Melero, Carlos Noreña (Madrid), Emilio Bobadilla, Santos Villa, F. Varona Murias, Dr. García Enseñal, O. Fonts Sterling, Miguel Ángel Melero (París) y Julián Silveira. El secretario de redacción era Ángel del Cerro. La redacción y administración de este semanario se ubicaba en Reina número $5 \mathrm{y}$ salía todos los jueves (El Sport 1886, p. 7). La información brindada por este periódico señala que en 1886 existían los clubes de beisbol Colón y Marianao. Este último disponía de un campo de juego de este deporte. Asimismo, se sabe que en la playa de Marianao se realizaban regatas de yates y en el Circo Teatro de Jané se efectuaban carreras de caminatas entre andarines ( $E l$ Sport, 1886). Para el año antes citado se tiene que don Celso Golmayo -campeón de ajedrez de Cuba- se enfrentaba a don Clemente Vázquez -cónsul de México en Cuba- quien era el campeón mexicano de 
esta disciplina deportiva. Otros ajedrecistas cubanos lo eran los señores Carvajal, Gunsberg, Burn y Zukertort. Un lugar preferido para las partidas de este deporte era el Unión Club (El Sport, 1888).

Por otra parte, el periódico en mención consigna que el Club Almendares B.B.C. era el campeón de beisbol cubano al ganarle al Club Habana B.B.C. por un marcador de 8 carreras contra 4. Los jugadores del Almendares eran: Carlos Maciá, pitcher; Ignacio García, catcher; Francisco Delabat, primera base; Ricardo Martínez, segunda base; Ramón García, jardinero central; Ramón Hernández, tercera base; Alfredo Arango, jardinero derecho; Francisco Salabarria, jardinero izquierdo; Aquiles Martínez, short stop y B. Hernández. El equipo del Habana B.B.C. estaba integrado por: Francisco Saavedra, jardinero izquierdo; Gustavo Aróstegui, short stop; Pablo Ronquillo, center filder; Antonio García, primera base; Alejandro Castillo; Fernando Santana, catcher; Rafael Hernández, segunda base; Adolfo Lujan, pitcher; Víctor Planas, right filder y José Lujan, tercera base (El Sport, 1886). El club Habana tenía su campo de juego en el Vedado (El Sport, 1887). Otro club pelotero capitalino era el Club Fe. Además, se conoce que en la ciudad de Matanzas el Círculo de la Juventud Liberal trataba de establecer un campo para la práctica del beisbol en el lugar que ocupan los edificios de la Exposición (El Sport, 1886). Para el domingo 22 de agosto del año en estudio se efectuarían en el Club Gimnástico -localizado en Prado No. 86, cuyo propietario era don Aurelio P. Granadosvarios asaltos de esgrima. Con respecto a las competencias entre yates se dispone de la información que refiere que se daban en la playa de Marianao entre los señores Ernesto Longa y A. Moner, en sus botes Margarita y Rayo respectivamente ( $E l$ Sport, 1886).

Para el 12 de agosto de 1886 se sabe que se trataba de fundar un club de beisbol en Jovellanos. Asimismo, se conoce que en el puerto de Jagua se celebraron las fiestas en honor de la Patrona del poblado del Castillo (Cienfuegos). En estas festividades se llevaron a cabo varias competencias de regatas entre las siguientes embarcaciones: Bruja, de Jorge Fowler, manejada por él mismo; Golondrina, de T. Mazarredo, guiada por Jaime Orozco; Jagua, de Isidoro O' Bourke; patronado por Pedro J. Orozco; Lola, de J. R. Jova, dirigida por su dueño; Io, de Carlos Fowler, piloteada por Elías Pombert (hijo); y Marina, de M. de la Torre, dirigida por Juan Salas. Las naves llegaron en el siguiente orden: 1. Bruja, 2. Golondrina y 3. Jagua (El Sport, 1886). Por otra parte, para el 19 de agosto del año en mención, se conocía que para la estación de invierno quedaría constituido, en La Habana, el Club de Velocipedistas (El Sport 1886). Para el 26 de agosto, se publicó que en la noche del sábado 11 de setiembre de 1886 el Club Almendares B.B.C. efectuaría un baile en los salones del club social "La Caridad del Cerro" ( $E l$ Sport, 1886, p. 4).

Con respecto al inicio de las prácticas deportivas en Cuba, se tiene que el 2 de setiembre de 1886 salió a luz el artículo de Julián Silveira Gálvez titulado: "Sports en Cuba", donde se refiere que cuando el beisbol se introdujo en la isla, solamente poca afición asistía a los partidos que 
celebraban los clubes Almendares, Habana y Matanzas, que fueron los primeros en fundarse. El número de estas asociaciones fue creciendo rápidamente con la llegada de los clubes Colón, Esperanza, Progreso, Fe, Siboney, Caridad del Cerro, etc. También se crearon otras corporaciones deportivas sin ingresar a la Liga de Beisbol, tales como el Oriente, Tínima, Unión, Guanabacoa, Alarma, etc. Para 1886 existían los clubes peloteros capitalinos Acacia, Athletic y Philadelphia, los cuales algunas veces jugaban en el campo Carlos III. Estas dos últimas eran asociaciones deportivas profesionales (El Sport, 1886). En la población de Cárdenas funcionaban las asociaciones beisbolísticas: Cárdenas, Esperanza, Vesubio e Intrépido. Asimismo se conoce de las prácticas de Mascotte, del Perico, Invencible de Jovellanos y uno de Cimarrones. Además, se sabe que en Guanajay funcionaban dos clubes de beisbol, y uno en Guaraguasí, en Guara. En Guanabacoa existían el Azul y el Carmelita. En Sagua funcionaban el Sagua y el América. En Pinar del Río existían los clubes Guamá y Danubio.

Para enero de 1887 se sabe que el Club Boston de Guanajay celebraría una serie de partidos con el club de San Antonio de los Baños. Un grupo de jóvenes estudiantes de la Escuela de Agricultura formarían parte del primero (El Sport, 1887). En La Habana funcionaban las asociaciones peloteras Caibarien, Remedios ( $E l$ Sport, 1887) y Carmelita (El Sport, 1887). También en 1887 existían en la capital los clubes Fénix, Fígaro (El Sport, 1887), Sport (El Sport, 1887), América (El Sport, 1887), Olivette, Washington (El Sport, 1887), Bacardi (El Sport, 1887,), Saint
Louis (El Sport, 1887), Azules (El Sport, 1887) y Ceiba (El Sport, 1887). Para mayo de 1888 funcionaba en la capital el club Regla (El Sport, 1888). En junio del año antes citado se sabe del funcionamiento del club Habanista, del Carmelita (El Sport, 1888) y del Campo Eliseos (El Sport, 1888).

Hacia mediados de 1887 en Cárdenas existía el club pelotero El Artesano. En Cárdenas funcionaban el Bocaccio, el Norma (El Sport,1887) y el Esperanza (El Sport, 1887). Para 1888 en esta misma localidad existía el club Varadero ( $E l$ Sport, 1888). En tanto que en Matanzas jugaban las asociaciones Cuba y Ultimátum (El Sport, 1887). El club matancero Progreso contaba con su propio terreno de juego donde competían, el Libertad con el Niágara (El Sport, 1888). Para el domingo 26 de junio del año en mención, se sabe que se enfrentarían en el terreno de Carlos III los clubes habaneros Fraternidad y Comercio, los cuales estaban integrados por negros (El Sport, 1887). Este era el primer partido de beisbol de negros en Cuba, y habían acordado realizar dos más. El encuentro deportivo lo ganó el Comercio por 12 carreras contra 10 del Fraternidad. Del Comercio sobresalieron: José Corzo, Cachaza y Arandia; del Fraternidad: García, Valle, Cervantes, García, Azoi, Flores, Corzo, Morales y Cárdenas (El Sport, 1887). Pese a la discriminación contra la población afrodescendiente en la isla, esta encontró en el beisbol un mecanismo de romper con esta y asimilar la cultura anglosajona. Para Ferrer la discriminación limitó la formación de la ciudadanía en la isla (Ferrer, 1991, 1995a, 1995b y 1998). 
En Santa Clara, en los terrenos de Bolanger, jugaban los clubes Santa Clara y Bélico (El Sport, 1887). Para noviembre de 1887 se habían formado en Cayo Hueso llamados Azul, Bando Panzó, Intrépido y Progreso. Un señor apellidado Gato había cedido un terreno para la realización de partidos y ayudar con los gastos en que se incurriera en tales eventos deportivos. Las cuatro asociaciones deportivas habían formado una liga con la presidencia de J. E. Cartaya (El Sport, 1887). En febrero de 1887 se había fundado en Santa Clara una asociación pelotera llamada Bacardi ( $E l$ Sport, 1888). Un factor que permitió la expansión del beisbol en Cuba fue la práctica entre infantes. Para el domingo 18 de setiembre de 1887 se efectuó, en los terrenos del Bacardi, en Vedado, un partido entre el Almendares Infantil y el Unión (El Sport, 1887). Otro factor lo constituyó el dedicar partidos a obras de beneficencia, como lo fue el partido que se efectuó entre Azules y Rojos a beneficio de las Escuelas Dominicales de La Habana (El Sport, 1888).

Según se ha podido comprobar, el desarrollo del deporte en Cuba, durante los años de estudio, se concentró en el occidente del país. Esto se debió a las diferencias socio-poblacionales entre las mitades oeste $\mathrm{y}$ este de la isla. Esta última estuvo aislada y poco poblada hasta inicios del siglo XX, cuando la extensión de los ingenios por esta zona fue equilibrando la situación. Para Santamaría y Naranjo, las diferencias entre el este y el oeste son esenciales para conocer la historia de Cuba decimonónica; por ejemplo, los estudios sobre esclavitud indican una menor implantación del sistema esclavista en el oriente, incluso relaciones más paternalistas entre amos y siervos que facilitaron la abolición; esto, el citado aislamiento y menor desarrollo de la zona, que la administración colonial no pudo resolver (se frustraron muchos proyectos de colonización y también la construcción de un ferrocarril que surcase toda la isla por la divisoria de aguas), explican que su territorio fuese el foco de todas las rebeliones contra aquella (Santamaría García y Naranjo Orovio, 2005). Otros elementos que permitieron que la práctica de deporte se concentrara en el occidente fue que allí estaba el capital y la infraestructura necesaria para la ejecución de actividades deportivas.

Las carreras de caballos comenzaron como un pasatiempo privado que se efectuaba en las no muy buenas calzadas habaneras. Posteriormente el Club Almendares creó una pista para estas competencias en sus terrenos particulares. Luego vino la creación del hipódromo de Marianao, donde tomaron parte entusiastas como Cortina, Fernández, Carlos Carbonell, León, Alberto Jorrin y Moliner, Cárdenas, Charles Todd, etc. En 1886 se estableció el hipódromo del Jockey Club de Colón. Para el 7 de enero de 1887 quedó constituida la directiva de la mencionada asociación deportiva: Presidente, Lic. Julián Godínez; vicepresidente, Simón Daykin; tesorero, Lorenzo López; secretario Gustavo Ferreti; vocales, Ramón López, Alejandro Gravier, Domingo Agos y Fidel Laredo (El Sport, 1887). Su hipódromo se inauguró el domingo 23 de enero de 1887 a las tres de la tarde. La primera carrera fue una competencia de dos vueltas al hipódromo en un solo lance y fue ganada por "Guineo" de don Ramón López. La segunda carrera consistía en una vuelta de 1.200 metros y fue conquistada 
por "Atrevido" de don Juan Santos Hernández. La tercera carrera era a paso nadado, pero como solo se presentó un caballo, no se llevó a efecto. En la cuarta carrera que consistía en una vuelta al escape, fue dominada por "Caimito". La quinta carrera era una vuelta al gualtrapeo, su vencedor fue "Chiquito" de don Victoriano García. En la sexta competencia que era una vuelta al escape, ganó "Conguito" de don Ramón López. La séptima carrera, también una vuelta al escape, la dominó "Caimito". En la octava y última carrera, que era de guerra al escape, el ganador fue "Indio" de siete años y seis medias cuartas de alzada, propiedad del pardo don Aurelio Álvarez. "Indio" hizo la vuelta en un minuto con cuarenta y un segundos y media decima (El Sport, 1887). Para marzo de 1887 en el hipódromo de Colón se realizaban competencias entre jinetes de Colón, Cienfuegos y Lajas (El Sport, 1887). En diciembre de 1887 se planeaba establecer un hipódromo en Villaclara (El Sport, 1887).

Sobre la ejecución de la gimnasia, se conoce que los principales practicantes eran Armenteros, Albertini, Jorrin, Valdés, Mañas, Filiberto Fonts, Sterling, Parajon, Eduardo G. Lebredo, Ebra, Marcos A. Longa, etc. Para 1887, por iniciativa de varios jóvenes de Sancti Spiritus, se planeaba un gimnasio, el cual se ubicaría en la calle Real 90. Entre los promotores de este proyecto sobresalían los señores César Cancio y Eduardo Álvarez (El Sport, 1887). El dato anterior permite ubicar la concentración de la actividad deportiva cubana durante el período de estudio en el occidente de la isla: desde Sancti Spiritus hasta Pinar del Río. Acerca de las competencias de yates de vela, se sabe que hacia
1880 únicamente existían en La Habana las naves que habían adquirido en Estados Unidos el señor capitán del puerto, Charles Todd y dos o tres más pertenecientes a entusiastas aficionados. Para 1886, las principales embarcaciones de este deporte eran "El Margarita", "Rayo", "Aline", "María, Emelina", "Dos Hermanas" y "Espumas de Mar", cuyos dueños eran los señores Marcos A. Longa, Moner, Charles Todd, Salmon, Ferrán, Méndez y Scull. Con respecto a las competencias de botes al remo se sabe que en la ciudad de Matanzas se había verificado una entre tres embarcaciones: "Club Hope", tripulación: Drake, Tolon, E. Poujaud, remeros, timonel, Hernández; "Cizne”, remeros: Abali, E. Janette, Hernández y Clark, timonel F. Hernández; "Iris", remeros, Lovio, Jimeno, González y Alfonso, timonel F. Hernández. Asimismo lucharon repetidas veces en la bahía de Jagua (Cienfuegos) los veloces sculls de cuatro remos Jagua y Fernandina. En la capital solo existían dos pequeñas y ligeras canoas pertenecientes a los señores Mendoza y Longa. Además, funcionaba el Havana Yatch Club, que sesionaba en la calle de Virtudes 75, casa de habitación de don Antonio Bollag.

La esgrima fue introducida en Cuba por el italiano Galleti. Acerca de este europeo se sabe que llegó a Cuba por los años 1840, y formó parte de la orquesta de una compañía de ópera que ocupó el Teatro de Tacón. En La Habana fundó la sala de armas del Gimnasio Normal y dio clase en el Círculo de Tiradores (El Sport, 1888). La escuela de esgrima francesa en la isla era practicada por Cordelois, Dr. Federico Mora, Gregorio Piquero, Antonio Maciá, Aurelio P. Granados, Manuel Cardenal, Ignacio 
Agramonte y otros. En el sable sobresalían José Martínez O., Núñez, Almeida y otros. Otros lugares de práctica eran el local del club Gimnástico y el Círculo Militar. En las armas de fuego se destacaban los tiradores Centelles, Matiartu, Miguel Andux y Jimeno, Mediavilla y Antolín Martínez. Acerca de la natación, se conoce que los principales practicantes de este deporte eran los señores de apellido Pedro, Andux, Granados, José de Armas y Cárdenas, Eduardo Zaldo, Longa, Méndez, profesor Manuel J. García, Calvo, Carbonell, Todd, etc. En 1887 funcionaba la sala de armas de don Manuel Alonso (El Sport, 1887). Otro lugar de prácticas de esgrima eran los salones de la "Colla de Sant Mus" (El Sport, 1887, p. 5). En 1887 funcionaban la Sala Granados (que era la del Club Gimnástico) (El Sport, 1887), la de don Francisco Álvarez en Luyanó (El Sport, 1887) y una sala de armas en Colón (El Sport, 1887). A mediados de 1888 fue fundado el Club de Esgrima capitalino en el Teatro Habana ( $E l$ Sport, 1888). También se conoce del funcionamiento de la asociación de esgrima Círculo del Vedado (El Sport, 1888).

Por otra parte, miembros del Club Almendares se dedicaban a la ejecución del cricket, fútbol y carreras de velocípedos, donde sobresalían los señores Cay, Albertini, Vega, etc. Acerca del patinaje la más sobresaliente en los salones de "La Caridad" de Albisu y del Skating Rink fue la conocida aficionada Abdulia Díaz. En el área varonil destacaron los señores Maciá, los hermanos Montemar, Alfredo Arango, Ramiro Mazorra, etc. En Matanzas también se distinguió Federico Delgado. Con toda esta información el cronista Silveira pretendía desmentir la idea existente de que los jóvenes cubanos eran afeminados (El Sport, 1886). En 1884 se fundó el Field Sport, una sociedad de caza de La Habana, luego en 1887 se denominó Sociedad de Caza de La Habana. La misma fue establecida por los señores Emilio A. Prida, J. Clairac y E. Wilson. Otros entusiastas eran el Marqués de Sandoval, J. Pérez Gentein y R. Narganes (El Sport, 1887). Para mediados de 1887 se conoce que en los terrenos de juegos del club Almendares se efectuaban tiros al pichón $(E l$ Sport, 1887). Sobre el billar se sabe que en 1887 el campeón cubano Alfredo Oro había vencido dos veces al estadounidense J.L. Malone en Nueva York, a las carambolas con tronera (El Sport, 1887).

Para finales de abril de 1887, los socios del Club de Ajedrez de La Habana eran los siguientes: Adolfo Moliner, Aureliano Medina, Emilio Hidalgo, Gabriel Toscano, Andrés C. Vásquez, Enrique Delmonte, Celso Golmayo, Guillermo Bernal, Antonio Gavilán, Alberto Ponce, Vicente Carvajal, Francisco Carricarte, Fernando Falangon, Manuel G. Echeverría, Enrique Conill, Arístides Martínez, Manuel Maruri, Ignacio Cervantes, Aurelio Mitjans, Álvaro Caballero, Antonio Armand, Rosendo Martínez, Juan Montenegro, José Reyes Guzmán, Cándido Sicarez, Hubert de Blanck, Joaquín Lastres, Ramón María Iglesias, Miguel Valdés Chacón, Manuel Gómez Petit, José Martín Rivero, Tomás Ruíz, Ramón Pardo, Saturnino Navarrete, Adolfo Nuño, Eduardo García, Joaquín García, Andrés Carrillo, César de la Guardia y Dr. F. Giralt (El Sport, 1887). 
Acerca de la halterofilia, se tiene la información que señala que el 9 de junio de 1887 se efectuó una competencia entre J. F. Noroña y Antonio P. Utrera, la cual consistía en hacer en 10 horas 500 pares de barras. Estas medían 3.58 metros de largo, por $0.52 \mathrm{~m}$. de ancho interior. Los contendientes comenzaron a las siete y media de la mañana y terminaron a las tres y cincuenta y dos minutos de la tarde. El señor Noroña que pesaba 110 libras, hizo las primeras 300 en dos horas y cincuenta y cinco minutos; y el señor Utrera que pesó 149 libras hizo 269 en el mismo tiempo. Este último experimentó los 100 pares, un fenómeno de contractibilidad en los músculos gemelos e hizo, por lo tanto, 400 pares puramente de hombros (El Sport, 1887).

Hacia finales del siglo XIX en Cuba se comienza a enfatizar un discurso que promueve el deporte como una forma "civilizada" de diversión frente a las prácticas tradicionales de entretenimiento. Con respecto a las corridas de toros El Sport señala que: "son un espectáculo archi-bárbaro, sin objeto que lo disculpe y cuyos resultados se limitan a halagar los instintos sanguinarios del pueblo inculto". En contraposición refiere que el beisbol: "como juego atlético, tiene por objeto desarrollar el cuerpo y con él la inteligencia (El Sport, 1886, p. 3)"'. El deporte en la isla, en los años de estudio, se popularizó a través de su inclusión en las actividades de las fiestas tradicionales, donde competía con las formas de diversión heredadas de la colonia. Esto se ilustra con el hecho de que para el domingo 3 de octubre de 1886, con motivo de la festividad de San Jerónimo, patrono de Puentes Grandes, entre los actos de celebración se realizarían "una cucaña sobre el río, con premio, carreras de cerdo ensebado, regatas de bote al remo, y carreras de caballos criollos al gualtrapeo, paso nadado o al escape" (El Sport, 1886, p. 5).

Sobre el papel de la mujer en el deporte, se sabe que en diciembre de 1886 el club de beisbol Guamá de Pinar del Río había constituido su directiva de honor con las siguientes señoritas: Presidenta, Teresa Fuguet; secretaria, María Pintado; tesorera, Virginia Ponzoa; vocales, Leopoldina Valdés, María Lancis, Florinda Laviña y Esperanza Pereda (El Sport, 1886). Acerca del tenis femenino se tiene que en agosto de 1888, en el barrio habanero del Vedado, existían dos canchas, una, la mejor, se ubicaba en la calle del Paseo esquina sétima propiedad de los señores Franke, en la que jugaban dos clubes formados por varias jóvenes entre las que figuran las señoritas Benítez y Gálvez; otro, en la esquina de las calles novena y décima, en la que jugaban las señoritas Bruzón, Carranza, Vega, Valdés, Sicouret, Ordoñez, Domínguez, Toscano, Freixas, Portillo y Segura y los señores Domínguez, Moré, Toscano, Koly, Portillo y Freixas. Casi todas las personas antes citadas también practicaban el croquet. Otro campo de croquet se encontraba en la casa del señor Mayen en las calles A y tercera; y en él juegan, entre otras, las señoritas Mayen, Govantes, Aguirre y los señores Govantes, Moré y Aguirre. Asimismo, se conoce que practicaban el remo en el río Almendares, las señoritas Alfonso y Carranza y los señores Alfonso y Moré. Las señoritas antes nombradas aceptaron participar en una competencia de remo contra señoritas de la playa de Marianao. Las primeras competirían en el bote el "Lince" y las segundas en el "Azucena" 
(El Sport, 1888). Con respecto a los datos anteriores debe señalarse que el origen del deporte femenino cubano se ubica dentro de un contexto general de diversiones, cuya práctica social excluyente hizo que se creara una división marcada con respecto a los sectores que las ejecutaban. Las primeras mujeres deportistas cubanas aprendieron el deporte a través de sus relaciones socioafectivas con miembros masculinos de la burguesía nacional y de las principales colonias extranjeras radicadas en el país. El hecho de que la mujer cubana solo fuera miembro honoraria de un club de beisbol o se dedicara a la práctica del tenis, del croquet y del remo, se explica por el hecho de que la práctica del deporte por parte de la mujer occidental ha tenido un enfoque sexista, sustentado en mitos y estereotipos. De hecho el género es un factor de discriminación en la práctica deportiva, ya que existen disciplinas que supuestamente son más apropiadas para los hombres y otras que son más convenientes para las mujeres (García y Asins, 1994).

La estructuración del deporte a lo largo del siglo XIX en una Inglaterra capitalista, cuya conformación social se fue cimentando en lo industrial y lo urbano, influenciada por el ideal social victoriano, se creó por parte de la burguesía para modelar el comportamiento de sus hijos varones con base en lo varonil y una visión filosófica que mantenía a las mujeres en una situación de discriminación, alejadas de estas nuevas prácticas de ocio (Barbero, 1993). Estas imágenes se fundamentaban en ideas erradas gestadas dentro de la profesión médica, y que ayudaron a mantener a la mujer alejada del deporte e incluso a interiorizar su incapacidad para ejecutar tales actividades. Según Vázquez, la concepción histórica del cuerpo femenino se sitúa en la base de la educación de la mujer y en concreto de la influencia de la educación física a la que ha estado sometida. Tradicionalmente la imagen histórica de la mujer ha sido biologista y ha estado marcada por su sexo genético que le posibilita la capacidad de procrear. Esto ha imposibilitado que la mujer no se posesione de su corporeidad desde la libertad personal, propiciándose, en cambio, la idea de que el cuerpo de la mujer no es un cuerpo para ella sino un cuerpo para los demás: primero como madre y receptora de los hijos e hijas; luego como conquista y posesión del varón para el que debe estar bella y se debe preservar; y por último, como reproductora de la propia sociedad (Vázquez, 1987). La imagen de femineidad victoriana le imponía a las mujeres conservarse frágiles y elegantes, sin adquirir las capacidades propias de unas deportistas: la fuerza, resistencia, independencia y actividad (Díez García, Alejandro, 2006).

\section{Conclusión}

La práctica del deporte en Cuba entre 1886 y 1888 se debió a la vinculación que este país efectuó con el sistema económico mundial por medio del cultivo de la caña de azúcar. A través del estudio de El Sport se pudieron comprobar varios hechos que marcaran la apropiación del deporte en Cuba y América Latina, como el de que su ejecución se realizó en el ámbito de lo privado y se concentró a nivel de geográfico en el occidente de la isla, entre Matanzas y Pinar del Río, principalmente, ya que allí se concentraba el capital proveniente de la actividad azucarera, los mejores centros 
educativos y medios de comunicación que permitían concertar encuentros deportivos. La práctica de las diferentes disciplinas fue acaparada por la nobleza española y la elite económica cubana junto con algunos grupos de miembros de las colonias estadounidenses y europeas.

La vida deportiva cubana de los años de estudio fue muy intensa, debido a la gran influencia cultural y a la cercanía con los Estados Unidos. Esto se reflejó, sobre todo, en el beisbol, pues su popularidad se debió a que reforzó el sentimiento local entre poblaciones como La Habana, Matanzas, Pinar del Río y Cárdenas, principalmente. Asimismo, su expansión radicó en que permitió la práctica de negros y de niños, incluyó a las mujeres como socias honorarias y dedicó partidos a la beneficencia. A través del estudio de la nomenclatura de los clubes peloteros se infiere que esta disciplina ayudó a consolidar un sentimiento de pertenencia nacional, con nombres como Cuba y Caridad. La práctica del deporte fue dominada principalmente por varones, por la visión sexista que existía de este. Durante los años de estudio, la mujer cubana solo ejecutó el tenis, el croquet y el remo.

\section{Referencias}

Barbero, Jesús. (comp.). (1993). Materiales de sociología del deporte. Madrid: Las Ediciones de la Piqueta.

Balboa, Imilicy; Barcia, María del Carmen; de la Torre, Mildred; García, Gloria y Vinat, Raquel.(1998). La turbulencia del reposo: Cuba, 1878-1895. La Habana, Ciencias Sociales
Crispín Castellanos, Douglas. (s. f.). Desarrollo deportivo cubano antes $y$ después de 1959. Recuperado de https://www.upo.es/revistas/index. php/materiales_historia_deporte/ article/view/499/692

Díez García, Alejandro. (2006). Evolución histórica y social de la presencia de la mujer en la práctica física y del deporte. Recuperado de http://www. efdeportes.com/efd99/mujer.htm

El Sport, Jueves 5 de agosto de 1886. Año I, No.43.

El Sport, Jueves 12 de agosto de 1886. Año I. No.44.

El Sport, Jueves 19 de agosto de 1886. Año I. No.45.

El Sport, Jueves 26 de agosto de 1886. Año I. No.46.

El Sport, Jueves 2 de setiembre de 1886. Año I. No.47.

El Sport, Jueves 9 de setiembre de 1886. Año I. No.48.

El Sport, Jueves 30 de setiembre de 1886. Año I. No.51.

El Sport, Jueves 11 de noviembre de 1886. Año II. No.6.

El Sport, Jueves 24 de diciembre de 1886. Año II. No.12.

El Sport, Jueves 13 de enero de 1887. Año II. No.15.

El Sport, Jueves 20 de enero de 1887. Año II. No.16.

El Sport, Domingo 23 de enero de 1887.

El Sport, Jueves 27 de enero de 1887. Año II. No.17.

El Sport, Jueves 10 de febrero de 1887. Año II. No.19. 
El Sport, Jueves 24 de febrero de 1887. Año II. No.20-21.

El Sport, Jueves 31 de marzo de 1887. Año II. No.26.

El Sport, Jueves 7 de abril de 1887. Año II. No.27.

El Sport, Jueves 28 de abril de 1887. Año II. No.30.

El Sport, Jueves 16 de junio de 1887. Año II. No.37.

El Sport, Jueves 23 de junio de 1887. Año II. No.38.

El Sport, Jueves 30 de junio de 1887. Año II. No.39.

El Sport, Jueves 14 de julio de 1887. Año II. No.41.

El Sport, Jueves 21 de julio de 1887. Año II. No.42.

El Sport, Jueves 4 de agosto de 1887. Año II. No.44.

El Sport, Jueves 11 de agosto de 1887. Año II. No.45.

El Sport, Jueves 18 de agosto de 1887. Año II. No.46.

El Sport, Jueves 25 de agosto de 1887. Año II. No.47.

El Sport, Jueves 15 de setiembre de 1887. Año II. No.50.

El Sport, Jueves 6 de octubre de 1887. Año II. No.1.

El Sport, Jueves 13 de octubre de 1887. Año II. No. 2 .

El Sport, Jueves 15 de setiembre de 1887. Año II. No.50.

El Sport, Jueves 29 de setiembre de 1887. Año II. No.52.

El Sport, 6 de octubre de 1887. Año II. No.1.
El Sport, Jueves 10 de noviembre de 1887. Año II. No.6.

El Sport, Jueves 24 de noviembre de 1887. Año II. No.8.

El Sport, Jueves 1 de diciembre de 1887. Año II. No.9.

El Sport, Jueves 15 de diciembre de 1887. Año II. No.11.

El Sport, Jueves 5 de enero de 1888. Año III. No.14.

El Sport, Jueves 9 de febrero de 1888. Año III. No.18.

El Sport, Jueves 1 de marzo de 1888. Año III. No.21.

El Sport, 13 de abril de 1888. Año III. No.25.

El Sport, Jueves 27 de mayo de 1888. Año III. No.31.

El Sport, 13 de junio de 1888. Año III. No.33.

El Sport, 27 de junio de 1888. Año III. No.35.

El Sport, 20 de julio de 1888. Año III. No.37.

El Sport, 13 de agosto de 1888. Año III. No.40.

El Sport, 27 de setiembre de 1888. Año III. No.49.

Ferrer, Ada. (1991). "Social Aspects of Cuban Nationalism: Race, Slavery, and the Guerra Chiquita, 18791880". Cuban Studies, 21.

Ferrer, Ada. (1995a). Esclavitud, ciudadanía y los límites de la nacionalidad cubana: La Guerra de los Diez Años, 1868-1878. Historia Social, 22.

Ferrer, Ada. (1995b). To Make a Free Nation: Race and the Struggle for Independence in Cuba, 1868-1989 (Ph. D. Diss.). University of Michigan. 
Ferrer, Ada. (1998). Rustic Men, Civilized Nation: Race, Culture and Contention on the Eve of Cuban Independence. Hispanic American Historical Review, 78.

García Álvarez, Alejandro. (1993). Los traficantes del Golfo. Historia Social, 17.

García Álvarez. Alejandro y Naranjo, Consuelo (Coords.). (1998). Monográfico Cuba 1898. Revista de Indias.

García, Milagros y Asins, Consuelo.(1994). La coeducación en educación física. Cuadernos para la Coeducación, 7.

García Rodríguez, Gloria. (1998). La sociedad cubana a fines de siglo. Cuadernos Cubanos de Historia, 1 .

González Echevarría, Roberto. (2004). La gloria de Cuba: Historia del beisbol en la isla. Madrid: Editorial Colibrí.

Guanche, Jesús. (1997). Aspectos etnodemográficos de la nación cubana: Problemas y fuentes de estudio. Debates Americanos, 3.

Gutiérrez, Antonio y Laviana, María Luisa (Coords.). (1998). Cuba entre dos revoluciones. Sevilla: Diputación Provincial.

Iglesias, Fe. (1997). El coste demográfico de la Guerra de Independencia. Debates Americanos 4.

Losada, Abel. (1994). Cambio demográfico y crecimiento económico en Cuba (1898-1958). Las primeras fases de la transición demográfica (Tesis doctoral). Universidad de Santiago de Compostela.

Naranjo. Consuelo y Mallo, Tomás (Eds.). (1994). Cuba, la Perla de las Antillas. Aranjuez: Doce Calles y CSIC.
Pujol, José, (Eds.). (1998). Cambio institucional e historia económica. Barcelona: Universidad de Barcelona.

Rodríguez Piña, Javier. (1990). Guerra de castas. La venta de indios mayas a Cuba, 1848-1861. México: Consejo Nacional para la Cultura y las Artes. Dirección General de Publicaciones.

Santamaría García, Antonio y Naranjo Orovio, Consuelo. (2005). La historia social de Cuba, 1868-1914. Aportaciones recientes y perspectivas. Nuevo mundo Mundos Nuevos. Recuperado de https://nuevomundo.revues.org/596

Tornero. Pablo. (1998). El peso del colonialismo. Integración y racismo en la Cuba de 1898. Rábida, 17.

Urbina Gaitán, Chester. (2001). Costa Rica y el deporte 1873-1921. Un estudio acerca del origen del fútbol y la construcción de un deporte nacional. Heredia: EUNA.

Urbina Gaitán, Chester. (2006). Origen del deporte en El Salvador (18851943). Realidad y reflexión, 17.

Urbina Gaitán, Chester. (2007). Deporte y Nación (1881-1950). El caso del fútbol en Guatemala. Ciudad de Guatemala: FLACSO.

Urbina Gaitán, Chester. (2015). Prensa, deporte y sociabilidad urbana en México DF (1851-1910). Revista de Ciencias Sociales, 149.

Vázquez, Benilde. (1987). Mitos, tradiciones y doctrina actual sobre la educación física de la mujer. Ponencia en Seminario Mujer y deporte, CSD. 